\title{
Systemic therapies for hepatocellular carcinoma: a recap of the current status
}

\author{
Petros Giovanis ${ }^{1}$, Manuela De Bona ${ }^{2}$, Fabio Farinati ${ }^{3}$, Andrea Buda $^{2}$, Riccardo Berletti ${ }^{4}$, Fable Zustovich $^{5}$, \\ Simona D'Ippolito', Michele De Boni ${ }^{2}$, Umberto Cillo ${ }^{3}$, Davide Pastorelli ${ }^{1}$

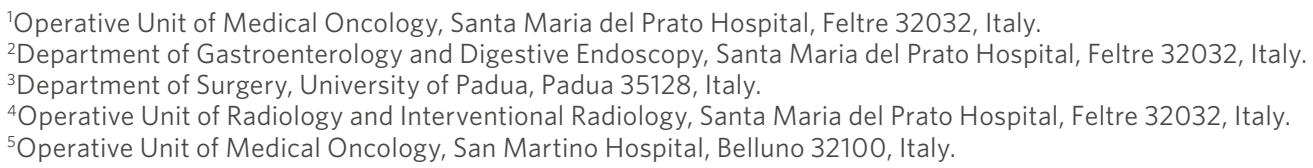

Correspondence to: Dr. Petros Giovanis, Operative Unit of Medical Oncology, Santa Maria del Prato Hospital, Via Bagnols sur Ceze 3 , Azienda Ulss 1- Dolomiti, Feltre 32032, Italy. E-mail: petros.giovanis@aulss1.veneto.it

How to cite this article: Giovanis P, De Bona M, Farinati F, Buda A, Berletti R, Zustovich F, D'Ippolito S, De Boni M, Cillo U, Pastorelli D. Systemic therapies for hepatocellular carcinoma: a recap of the current status. Hepatoma Res 2018;4:10.

http://dx.doi.org/10.20517/2394-5079.2018.21

Received: 18 Mar 2018 First Decision: 4 Apr 2018 Revised: 10 Apr 2018 Accepted: 13 Apr 2018 Published: 27 Apr 2018

Science Editor: Guang-Wen Cao Copy Editor: Guang-Zhe Zhu Production Editor: Huan-Liang Wu

\begin{abstract}
After decades of frustrating nihilism due to lack of innovative therapeutic solutions, the onco-hepatological community is facing up to important novelties for the treatment of intermediate and advanced stages of liver cancer. Four new drugs have been investigated and resulted in positive data: lenvatinib resulted not inferior to the standard of care sorafenib in first line, regorafenib and cabozantinib demonstrated prolonging survival in patients progressed to sorafenib and nivolumab approved by FDA as option after first-line. Contemporary, the knowledge acquired after ten years' experience of sorafenib in patient selection and adverse events management revealed an increase of the outcomes. Physicians dedicated to treat advanced and intermediated liver cancer are close to live a new era where systemic treatments could have a huge impact on the disease. The aim of this review is to anticipate this new approach at the disease, summarizing data currently available for these therapies to identify therapeutic strategies of sequences and choosing drugs according to the patient profile.
\end{abstract}

Keywords: Hepatocellular carcinoma, liver cancer, sorafenib, regorafenib, lenvatinib, cabozantinib, nivolumab

\section{INTRODUCTION}

In the last decade the outcomes of many oncologic diseases have been dramatically transformed consequently the introduction of novel therapies; moreover, the recourse to sequential or combination strategies allowed to achieve long term benefits in overall survival $(\mathrm{OS})^{[1,2]}$. This aspect is particularly

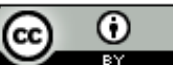

(C) The Author(s) 2018. Open Access This article is licensed under a Creative Commons Attribution 4.0 International License (https://creativecommons.org/licenses/by/4.0/), which permits unrestricted use, sharing, adaptation, distribution and reproduction in any medium or format, for any purpose, even commercially, as long as you give appropriate credit to the original author(s) and the source, provide a link to the Creative Commons license, and indicate if changes were made. 
evident in areas of oncology such as breast, colon or kidney cancer where the prognosis associated with these pathologies was only of some months few years ago, conversely therapeutic strategies allow to reach survivals quantifiable in order of years at present time ${ }^{[1]}$. Unfortunately, such therapeutic successes are still challenging for patients currently receiving diagnosis of intermediate or advanced stage of hepatocellular carcinoma (HCC), because of the restricted efficacy for systemic therapies. Such difficulty in finding an active systemic therapy is strictly related to the biology of HCC: differently than other oncological diseases, the primary malignancy of the liver occurs predominantly in patients with two diseases: the tumor and the underlying cirrhosis ${ }^{[3]}$. Therefore, if the single drug can slow down the oncological progression, the same drug may worsen the cirrhotic component of HCC leading the patient towards to exitus ${ }^{[3,4]}$.

Systemic therapies in liver cancer achieved the first important goal in 2007 when the introduction of the target agent sorafenib provided a therapeutic option for patients with HCC in progression or evaluated not suitable for locoregional treatments ${ }^{[5,6]}$. After this initial success, a sense of nihilism persisted in the oncology community in the subsequent decades due to failure of the new studies with molecular targeted agents to demonstrate a benefit in OS or time to tumor progression (TTP) or progression-free survival (PFS). Phase 3 trials failed to show superiority of sunitinib, erlotinib plus sorafenib, FOLFOX, doxorubicin, or non-inferiority of brivanib, linifanib to sorafenib in the first-line setting ${ }^{[6]}$. Similarly, the drugs brivanib, everolimus, linifanib, ramucirumab and tivantinib failed pivotal studies designed in second-line settings in patients progressing or intolerant to sorafenib ${ }^{[6]}$.

In this depressing scenario a turning point was reached very recently, after the announcement of positive results of the phase 3 studies conducted with new biological therapies. The first drug showing to prolong the overall survival sequentially to sorafenib was regorafenib ${ }^{[7,8]}$. After short time, lenvatinib resulted noninferior to sorafenib in the first line of treatment ${ }^{[7]}$, cabozantinib showed efficacy after sorafenib progression or in patients with intolerance to this drug ${ }^{[9]}$, and nivolumab received conditioned FDA approval for patients pretreated with sorafenib ${ }^{[10]}$. At the same time, the experience with sorafenib in HCC after many years increased outcomes in survival due to better patient selection and better adverse events management, encouraging the medical community to pursue excellence in disease management with this mature $\operatorname{drug}^{[11,12]}$.

The goal of this paper is to take stock the situation regarding systemic drugs evaluated in the intermediate and advanced HCC setting. We focused only on therapies which achieved positive results in phase 3 trials or an early approval by health authorities after phase $1 / 2$ conducted, and we tried to position every therapy according to data nowadays available.

\section{RADICAL THERAPIES VERSUS SYSTEMIC TREATMENTS}

Radical therapies are the most frequently used treatment in HCC and are represented by surgical resection, liver transplantation and the local destruction methods known as loco-regional therapies. These are able to turn out to the radical destruction of the tumor but they have never demonstrated to prolong OS in prospective phase 3 studies conducted on HCC populations with intermediate or advanced stage ${ }^{[13-15]}$. Therefore, current evidence indicates that potentially curative treatments result only for very early- and early-stage HCC.

The surgical treatments transplantation and resection are evaluated as potentially curative in early stages of the disease for carefully selected HCC patients, but are usually discouraged in advanced phases due to the high risk of hepatic decompensation and neoplastic progression in the frame time awaiting surgery ${ }^{[15]}$.

The BCLC algorithm reported transarterial chemoembolization (TACE) as the first-line treatment for the intermediate stage in HCC patients, however TACE may have high recurrence rates and should therefore not 
Table 1. Patient unsuitable for TACE or with absolute contraindications to CTACE according to ESMO 2012 guidelines

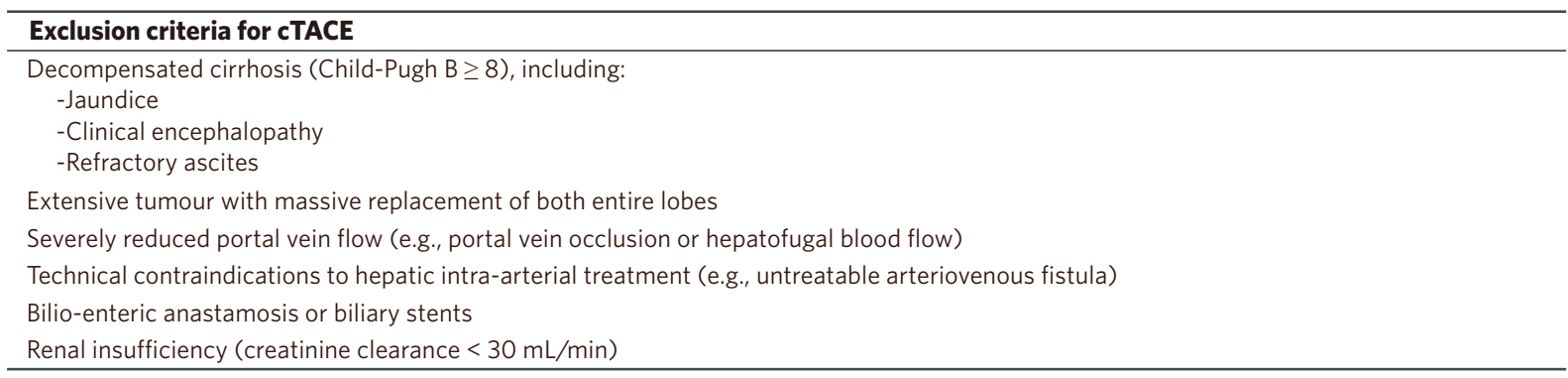

CTACE: conventional transarterial chemoembolization; ESMO: European Society of Medical Oncology

Table 2. When to stop TACE? Definition of TACE failure/refractorines

\begin{tabular}{|c|c|}
\hline Authors & Criteria for definition of TACE failure/refractorines \\
\hline Kudo et al. ${ }^{[62]}$ & $\begin{array}{l}\text { Intrahepatic lesion (> } 2 \text { consecutive incomplete necrosis; }>2 \text { consecutive appearances of a new lesion recurrence) } \\
\text { Appearances of vascular invasion } \\
\text { Appearance of EHS } \\
\text { Continuous elevation of tumor markers }\end{array}$ \\
\hline Yamanaka et al. ${ }^{[63]}$ & $\begin{array}{l}\text { TACE failure } \\
\text { Inability to select the feeding artery of the HCC because of arterial devastation; deterioration of liver function and/or } \\
\text { tumor thrombosis of the portal vein } \\
\text { TACE refractory } \\
\text { Repetitive tumor recurrence in the liver; appearance of vascular invasion; appearance of distant metastasis; continuous } \\
\text { increase in tumor marker levels after TACE }\end{array}$ \\
\hline AISF et al. ${ }^{[64]}$ & $\begin{array}{l}\text { The AISF expert panel considers failure of TACE the lack of objective response of the treated lesions after two procedures } \\
\text { (consider also a multi-disciplinary decisional setting) }\end{array}$ \\
\hline Sieghart et al. ${ }^{[21]}$ & ART score \\
\hline
\end{tabular}

TACE: transhepatic arterial chemoembolization; ART: assessment for retreatment with TACE

be considered a curative therapy ${ }^{[16-18]}$. This loco-regional treatment may not represent the only therapeutic option for this stage of patients because authors reported that TACE can deal good results in center with good experience after a careful selection of patients, but may also present technical difficulties and contraindication $^{[19]}$. Table 1 shows the main patients characteristics in which TACE is contraindicated, absolute and relative contraindications generally include features of decompensated liver disease, extensive bilobular tumor load and impaired integrity of the portal vein due to thrombosis or hepatofugal flow, as well as untreated large varices, massive tumor diameter, and severe co-morbidities.

A point of discussion is when to establish TACE failure/refractoriness and, consequently, patient should be switched to a different therapy. The lack of a clear definition of the right moment to stop the re-treatments with TACE due to failure or refractoriness may lead to unnecessary overtreatment with TACE that may worsen the liver function, precluding the opportunity to shift the patient to systemic treatments ${ }^{[20]}$. Table 2 summarizes the criteria identified to define the failure of TACE by experts and guidelines. The assessment for retreatment with TACE (ART) score is a simple validated algorithm useful for deciding the potential benefit of undergoing a third TACE evaluating three prognostic factors: the increase in aspartate transaminase (AST) level by more than $25 \%$, the increase in the Child-Pugh score and the absence of tumor response. TACE has a good prognostic effect on patients with ART score of $0-1.5$, while patients with ART score $\geq 2.5$ might have minor or even no prognostic benefits ${ }^{[21,22]}$.

Similarly, to TACE, the effectiveness of the intra-hepatic radioembolization (TARE) using microspheres loaded with yttrium-90, may depend on the operator's manual skills ${ }^{[23]}$. Table 3 reports levels of evidence associated to TARE by the principal international guidelines and recommendations; the use of TARE in HCC is supported by data based on retrospective series and uncontrolled prospective studies. Two randomized studies (SARAH and SIRVENIB), designed to show the superiority of TARE versus sorafenib, 
Table 3. Primarily International Guidelines and level of evidence associated to radioembolization

\begin{tabular}{ll}
\hline Guidelines & \multicolumn{1}{c}{ Recommendation } \\
\hline ESMO 2012 & $\begin{array}{l}\text { Revel of recommendation } \\
\text { as those with prior TACE failure, excellent liver function, macrovascular invasion and the } \\
\text { absence of extra-hepatic disease }\end{array}$ \\
& $\begin{array}{l}\text { Current phase } 3 \text { studies are evaluating the place of radioembolization versus TACE in } \\
\text { patients with intermediate stage HCC, and as single modality or combined with sorafenib in } \\
\text { patients with advanced HCC compared with sorafenib }\end{array}$ \\
AASLD 2010 & $\begin{array}{l}\text { Radioembolization with Yttrium90-labeled glass beads has been shown to induce extensive } \\
\text { tumour necrosis with acceptable safety profile. However, there no studies demonstrating an } \\
\text { impact on survival and hence, its value in the clinical setting has not been established and } \\
\text { cannot be recommended as standard therapy for advanced HCC outside clinical trials }\end{array}$ \\
\hline
\end{tabular}

TACE: transhepatic arterial chemoembolization; HCC: hepatocellular carcinoma

Table 4. Efficacious systemic therapies for HCC

\begin{tabular}{|c|c|c|c|c|c|}
\hline & Study & Arms & $\begin{array}{l}\text { OS benefit } \\
\text { (months) }\end{array}$ & HR & Adverse events (Grade 3-4) \\
\hline \multirow[t]{3}{*}{ 1st line setting } & SHARP $^{[5]}$ & $\begin{array}{l}\text { Sorafenib vs. } \\
\text { placebo }\end{array}$ & 10.7 (vs. 7.9) & 0.69 & $\begin{array}{l}\text { Hand-foot skin reaction ( } 8 \%) \text {, diarrhoea ( } 8 \%) \text {, fatigue (3), } \\
\text { hypertension (3\%) }\end{array}$ \\
\hline & ASIA PACIFIC $[26]$ & $\begin{array}{l}\text { Sorafenib } v s \text {. } \\
\text { placebo }\end{array}$ & 6.5 (vs. 4.2) & 0.68 & Hand-foot skin reaction (11\%), diarrhoea (6\%), fatigue (3\%) \\
\hline & SELECT $T^{[55]}$ & $\begin{array}{l}\text { Lenvatinib vs. } \\
\text { sorafenib }\end{array}$ & 13.6 (vs. 12.3) & 0.92 & $\begin{array}{l}\text { Hypertension ( } 23 \%) \text {, increased blood bilirubin (7\%), proteinuria } \\
(6 \%) \text {, elevate aspartate aminotransferase }(5 \%)\end{array}$ \\
\hline \multirow[t]{3}{*}{ 2nd line setting } & $\operatorname{RESORCE}^{[50]}$ & $\begin{array}{l}\text { Regorafenib } \\
\text { vs. placebo }\end{array}$ & 10.6 (vs. 7.8) & 0.63 & $\begin{array}{l}\text { Hypertension (15\%), hand-foot skin reaction (13\%), fatigue (9\%), } \\
\text { diarrhoea (3\%) }\end{array}$ \\
\hline & CELESTIAL ${ }^{[58]}$ & $\begin{array}{l}\text { Cabozantinib } \\
\text { vs. placebo }\end{array}$ & 10.2 (vs. 8.0) & 0.76 & $\begin{array}{l}\text { Hand-foot skin reaction (17\%), hypertension (16\%), increased } \\
\text { aspartate aminotransferase (12\%), fatigue (10\%) }\end{array}$ \\
\hline & $\begin{array}{l}\text { CheckMate } \\
040^{[59]} \\
\text { (expansion } \\
\text { cohort) }\end{array}$ & $\begin{array}{l}\text { Nivolumab } \\
\text { single arm }\end{array}$ & 15.6 & - & $\begin{array}{l}\text { Increased aspartate aminotransferase }(18 \%) \text {, increased alanine } \\
\text { aminotransferase }(11 \%) \text {, increased blood bilirubin }(7 \%) \text {, immune- } \\
\text { mediated hepatitis (5\%) }\end{array}$ \\
\hline
\end{tabular}

were conducted in patients with intermediate or advanced HCC no longer susceptible to TACE ${ }^{[24,25]}$. Both trials failed to demonstrate a survival benefit from transarterial radioembolization compared with sorafenib. Moreover, the median overall survival of patients treated with TARE resulted lower than sorafenib. In addition, in both studies a significant proportion of patients randomized to TARE never received the planned therapy (26.5\% and $28.6 \%$ of patients of TARE arm $v$ s. $7 \%$ and $9.0 \%$ in the sorafenib arm respectively in SARAH and SIRVENIB). This may suggest difficulties in selecting patients and implementing TARE procedure in clinical practice.

Worth to be mentioned is that these studies demonstrated only the inferiority of TARE to systemic treatment and not the non-inferiority. In fact, in study designs the hypothesis of non-inferiority had not been prespecified in the protocol.

\section{SYSTEMIC TREATMENTS FOR HCC}

Table 4 reports the efficacious systemic therapies in intermediate and advanced stage of HCC, estimated as therapies achieving successful in phase 3 trials or early approved by health authorities accounting for phase 2 data. A summary of the main studies currently available are described in this section.

\section{Sorafenib}

Sorafenib is an oral multikinase inhibitor that has antiangiogenic, anti-proliferative, anti-metastatic and anti-immunosuppressive activities. Sorafenib inhibits the activity of targets present in the tumour cell (CRAF, BRAF, V600E BRAF, c-KIT, and FLT-3) and in the tumour vasculature (CRAF, VEGFR-2, VEGFR-3, and PDGFR-ß). RAF kinases are serine/threonine kinases, whereas c-KIT, FLT-3, VEGFR-2, VEGFR-3, and 
PDGFR- $\beta$ are receptor tyrosine kinases. Sorafenib demonstrated a statistically significant improvement of OS in Child Pugh class A patients with intermediate or advanced HCC (BCLC stages B and C) in two large phase 3, randomized, placebo-controlled trials performed in Western countries (SHARP) and in Asia-Pacific (ASIA-PACIFIC) $^{[5,26]}$.

In the SHARP trial the OS and TTP were respectively 10.7 and 5.5 months (7.9 and 2.8 months respectively for the placebo group) ${ }^{[5]}$, while in the ASIA-PACIFIC trial OS and TTP were 6.5 and 2.8 months respectively (4.2 and 1.4 months for the placebo group ${ }^{[26]}$. The hazard ratios for OS and TTP were nevertheless comparable between the two trials, indicating similar magnitude of clinical benefit. The observed differences in median OS and TTP in these 2 trials were probably due to poorer disease characteristics of advanced disease in the ASIA-PACIFIC trial compared to the SHARP trial ${ }^{[27]}$. Subgroup analyses have shown that sorafenib consistently provides an OS benefit compared with placebo irrespective of baseline conditions such as disease etiology, baseline tumor burden, performance status, tumor stage, and prior therapy ${ }^{[5,26,28]}$.

A pooled global population enrolled in the two pivotal studies was analysed to identify potential predictive factors of sorafenib treatment benefit. This analysis turned out that sorafenib treatment provided a survival benefit across all categories of patients, showing a significant magnitude of benefit in patients with disease confined to the liver (without extrahepatic disease - EHS) or HCV cirrhosis or a low neutrophil-tolymphocyte ratio status ${ }^{[28]}$.

The efficacy and the safety profile of sorafenib already observed in clinical trials were confirmed in realworld experiences assessing sorafenib in patients who are not selected by strict clinical trial criteria, including patients with comorbidities and those receiving concomitant medication ${ }^{[29,30]}$.

Both in clinical and field-practice studies, the most frequent sorafenib-associated adverse events resulted in dermatological lesions as hand-foot skin reaction, fatigue and diarrhoea, whereas treatment-related liver adverse events are overall less frequently reported ${ }^{[31]}$. Single experiences reported that the occurrence of hypertension, diarrhoea and skin lesions are generally correlated to higher survival benefits, therefore the occurrence of some toxicities should be managed and not immediately address to discontinuation ${ }^{[32-36]}$. At this regard, treatment strategies based on temporary suspensions followed by restart of therapy at lower doses may help in management of sorafenib tolerance in patients presenting relevant adverse events.

The results collected showed poorer outcomes in patients with Child-Pugh B cirrhosis treated with sorafenib, when compared with patients with Child-Pugh A cirrhosis. This finding could be likely attributed to a more severe liver dysfunction and more compromised conditions of Child-Pugh B patients and not to an effect of the drug itself.

With the aim to extend the benefit observed with sorafenib to patients with earlier stages of disease (BCLC-A and B), many phase 2 and 3 trials were conducted to evaluate safety and efficacy of sorafenib in surgical adjuvant setting and in combination with loco-regional therapies ${ }^{[37-44]}$. All these studies did not achieved the primary endpoint, authors reported possible explanations due to the design of the studies. However new study of combination or in adjuvant setting are currently ongoing with different treatment schedules.

Failing results were observed also combining sorafenib with systemic therapies. Indeed, the two trials sorafenib plus erlotinib and doxorubicin plus sorafenib failed to show the superiority of the combination arms versus sorafenib alone as comparison $\operatorname{arm}^{[45,46]}$.

Currently sorafenib is the standard of care for advanced HCC as reported by many guidelines and the improvement of survival associated with this drug is supported by the highest level of evidence ${ }^{[47]}$. 


\section{Regorafenib}

Regorafenib is an oral multikinase inhibitor, targeting angiogenic, stromal and oncogenic receptors VEGFR1-3, TIE-2, RAF-1, BRAF, BRAFV600, KIT, RET, PDGFR, and FGFR ${ }^{[48]}$. Besides, studies in vivo reported that the drug can inhibit the factor CSF1R and to reduce levels of tumor associated macrophages, a factor implicated in the tumor-specific immune response and in tumor growth ${ }^{[48]}$. The drug was initially approved for colorectal cancer and for gastrointestinal stromal tumor by the main health authorities.

A phase 2 study conducted on 36 patients with intermediate or advanced HCC resistant to sorafenib reported that regorafenib presented acceptable tolerability and antitumour activity ${ }^{[49]}$. In the pivotal phase 3 study (RESORCE), more than 500 patients affected by advanced HCC with liver function Child-Pugh A and with ECOG PS 0-1, were randomised (2:1) to receive $160 \mathrm{mg}$ oral regorafenib or placebo plus best supportive care once daily for 1-3 of each four week cycle ${ }^{[50]}$. Patients were stratified for region, ECOG PS score, extrahepatic spread, vascular invasion and AFP.

Worth mentioning is that the study was designed with the aim to avoid enrolling patients potentially nonresponding to tyrosine kinase inhibitor (TKI). In fact, the RESORCE study admitted only patients with a documented radiological progression to sorafenib and tolerant to the drug (defined as receiving sorafenib $\geq$ $400 \mathrm{mg}$ daily for at least 20 of the last 28 days of treatment).

The results indicated significant improvements in the primary endpoint of OS [10.6 months with regorafenib vs. 7.8 months with placebo hazard ratio (HR) $0.63, P<0.0001$ ] besides the secondary endpoints PFS (3.1 vs. 1.5 months, HR 0.46; $P<0.001)$. These benefits were maintained across all subgroups. In addition, patients treated with regorafenib had significantly better overall response and disease control rate than best supportive care. After a median 3.8 months, patients treated with regorafenib presented a reduction of $38 \%$ of the risk of death and a $54 \%$ reduction in the risk of progression or death compared to placebo ${ }^{[50]}$.

The most common AEs grade $\geq 3$ in patients of the regorafenib group were hypertension (15.2\% regorafenib vs. $4.7 \%$ of the placebo group), hand-foot skin reaction ( $12.6 \% v s .0 .5 \%)$, fatigue ( $9.1 \% v s .4 .7 \%)$, and diarrhea $(3.2 \% \text { vs. } 0 \%)^{[50]}$.

Similarly to sorafenib, the survival subgroup analysis of RESORCE evaluating the incidence of skin lesions proposed that hand-foot skin reaction may be a marker for regorafenib activity: infactamong regorafenibtreated patients, OS was improved in patients who had HFSR at any time during the trial and who had their first HFSR event within the first cycle compared with those without HFSR during those periods (13.2 vs. 8.1 months, HR 0.66) ${ }^{[50]}$.

An additional exploratory analysis evaluating the global benefit of the sequence sorafenib-regorafenib showed that the median OS from the start of sorafenib was 26 months for the sequence sorafenib-regorafenib (whereas resulted 19.2 months in the sequence sorafenib-placebo) ${ }^{[51]}$.

Following this positive study, an indication expansion for regorafenib was approved in April 2017 in the USA, in May 2017 in Japan and in August 2017 in EU, allowing its use in second-line therapy for HCC.

\section{Lenvatinib}

Lenvatinib is a multitargeted TKI of the VEGFRs 1, 2, and 3, FGFRs 1-4, PDGFR $\alpha$, RET, and KIT signaling involved in tumor angiogenesis and malignant transformation ${ }^{[52]}$. Lenvatinib was approved at the dosage $24 \mathrm{mg}$ daily to treat patients with differentiated thyroid cancer refractory to iodine-131 therapy, later the drug was approved in combination with everolimus as a treatment for the second line of renal cell carcinoma at dosage $10 \mathrm{mg}$ daily ${ }^{[52,53]}$. 
Favorable outcomes were achieved in a phase 2 single-arm study on 46 patients with advanced HCC treated with $12 \mathrm{mg}$ of lenvatinib daily until progression or toxicity ${ }^{[54]}$. An independent review committee referred that the median in TTP was 7.4 months, the overall response rate evaluated by modified RECIST criteria (mRECIST) was 37\%, and the median OS was 18.7 months. The most common toxicities were hypertension, palmar-plantar dysesthesia, thrombocytopenia, anorexia and proteinuria. These adverse events leaded to dose reductions in $74 \%$ of the cases and drug discontinuation in $22 \%{ }^{[54]}$.

Basing on this phase 2 data, the following phase 3 trial (REFLECT) assumed that lenvatinib exposure was influenced by body weight. Consequently, the doses used in the REFLECT trial were $8 \mathrm{mg}$ for patients with weight $<60 \mathrm{~kg}$ and $12 \mathrm{mg}$ for others. In this phase 3 study, a total of 954 patients with unresectable HCC were randomized 1:1 according to an open-label, randomized, parallel-assignment, active-controlled protocol, to compare the efficacy of lenvatinib versus sorafenib as a first-line systemic treatment according to a non-inferiority design ${ }^{[55]}$. The primary endpoint of OS was initially evaluated for non-inferiority and then for superiority. The study excluded patients with 50\% or higher liver occupation, obvious invasion of the bile duct, or invasion at the main portal vein.

The primary endpoint of non-inferiority of lenvatinib in terms of OS compared with sorafenib was met: lenvatinib resulted not-inferior in mOS (13.6 months with lenvatinib and 12.3 months with sorafenib). Differently, the OS of lenvatinib over sorafenib was not achieved. Additionally, lenvatinib achieved significant and clinically meaningful improvement in PFS (7.4 vs. 3.7 months), TTP (8.9 vs. 3.7 months) and overall response rate ( $24 \% v s .9 \%$ by mRECIST). The median duration of treatment with lenvatinib was 5.7 vs. 3.7 months with sorafenib ${ }^{[55]}$.

Investigators detected that the treatment duration for lenvatinib arm was shorter than time to progression (5.7 vs. 8.9 months) and that this datum was not observed in the sorafenib arm (both 3.7 months). This could be related to a major incidence of lenvatinib definitive interruption before tumor progression probably due to a greather incidence of serious treatment emergent adverse events in the lenvatinib arm and not in the sorafenib arm.

In the two arms of the study, a similar level of treatment-emergent adverse events was observed for dose reductions (37\% of patients in the lenvatinib arm versus $38 \%$ in the sorafenib) and drug discontinuations (9\% vs. $7 \%$ respectively).

Lenvatinib showed an higher incidence of grade $\geq 3$ treatment-emergent adverse events (57\% vs. 49\%), and the most common grade $3 / 4$ treatment-emergent adverse events resulted hypertension ( $23 \%$ in lenvatinib arm vs. $14 \%$ of sorafenib), decreased weight ( $8 \%$ vs. $3 \%$ ), decreased platelet count ( $6 \% v$ s. $3 \%)$, elevated aspartate aminotransferase $(5 \%$ vs. $8 \%)$, decreased appetite $(5 \%$ vs. $1 \%)$, diarrhea $(4 \% v$ s. $4 \%)$, and palmarplantar erythrodysesthesia (3\% vs. $11 \%)^{[55]}$.

\section{Cabozantinib}

Cabozantinib is a tyrosine kinases inhibitor with activity directed to MET, VEGFR2, FLT3, c-KIT, and $\mathrm{RET}^{[56]}$. This drug was initially approved by FDA on November 2012 for the treatment of metastatic medullary thyroid cancer with dosage $140 \mathrm{mg}$ daily. In April 2016 Cabozantinib was approved for the second-line treatment of advanced renal cell carcinoma after prior antiangiogenic therapy while in renal cell carcinoma at dosage of $60 \mathrm{mg}$ daily.

Cabozantinib was also investigated in HCC patients as part of a phase 2 randomized discontinuation trial ${ }^{[57]}$; a cohort of 41 patients with HCC was treated with $100 \mathrm{mg}$ daily of drug, the disease control rate at 12 weeks was $68 \%$ with two partial responses. The efficacy resulted independent from a prior sorafenib 
therapy. Grade 3 and 4 adverse events included diarrhea (20\%), palmar-plantar erythrodysesthesia (15\%) and thrombocytopenia (15\%). More than the half of patients (59\%) required at least one dose reduction ${ }^{[57]}$.

In the randomized, double-blind, parallel-assignment, placebo-controlled phase 3 trial (CELESTIAL), 707 subjects with HCC were randomized according to a 2:1 ratio to receive cabozantinib at $60 \mathrm{mg}$ daily $(n=470)$ or placebo $(n=237)^{[58]}$. All the patients presented ECOG performance status of 0 or 1 , Child-Pugh score of A, and resulted progressed or intolerant to at least 1 prior systemic therapy for advanced HCC. Worth to be mentioned is that $28 \%$ of subjects received two prior systemic therapies regimen, therefore CELESTIAL study enrolled also patients receiving cabozantinib as third line of treatment. The primary endpoint OS resulted significant favorable to cabozantinib: 10.2 months compared with 8.0 months with placebo, representing the $24 \%$ reduction in the risk of death (HR 0.76; 95\% CI 0.63-0.92; $P=0.0049$ ). The PFS with cabozantinib was 5.2 months compared with 1.9 months for placebo, corresponding to the $56 \%$ of reduction in the risk of progression or death with the targeted therapy (HR $0.44 ; P<0.0001$ ). In the subgroup analysis of patients receiving only prior sorafenib, the median OS was 11.3 months with cabozantinib compared with 7.2 months for placebo (HR 0.70) ${ }^{[58]}$.

In the treatment arm resulted an increased number of patients discontinuing due to treatment-related adverse events, in particular the most common grade $3 / 4$ adverse events with cabozantinib resulted hand-foot skin reaction ( $17 \%$ vs. $0 \%$ in placebo arm), hypertension ( $16 \% v s .2 \%)$, increased aspartate aminotransferase ( $12 \% v s .7 \%)$, fatigue (10\% vs. $4 \%)$, and diarrhea ( $10 \%$ vs. $2 \%)$. In addition, cabozantinib arm presented a higher incidence of grade 5 adverse events; in fact, 6 patients died due to hepatic failure, esophagobronchial fistula, portal vein thrombosis, upper gastrointestinal hemorrhage, pulmonary embolism, and hepatorenal syndrome. The median duration of exposure resulted in 3.8 months and 2 months in cabozantinib and placebo arms respectively ${ }^{[58]}$. Notably, the discordance registered between PFS and DoE in the active arm versus the placebo one could be explained by the significant higher incidence of adverse events in the cabozantinib group that could have been led to an earlier treatment discontinuation, reflecting probably a not easy management of toxicities.

\section{Nivolumab}

Nivolumab in HCC was investigated in the CheckMate-040 trial, a multicenter, open label phase I/II study conducted from November 2012, to August 2016 in adults ( $\geq 18$ years) with histologically confirmed advanced HCC with or without hepatitis C or B (HCV OR HBV) infection. A previous sorafenib treatment was allowed ${ }^{[59]}$. The study enrolled 48 patients in a first dose-escalation phase and 214 patients in a subsequent dose-expansion phase. Primary endpoints were safety and tolerability for the escalation phase and objective response rate (evaluated by RECIST version 1.1) for the expansion phase.

In the escalation phase, patients received 0.1 to $10 \mathrm{mg} / \mathrm{kg}$ of IV nivolumab every 2 weeks. Nivolumab $3 \mathrm{mg} / \mathrm{kg}$ every 2 weeks was chosen for the dose expansion phase ${ }^{[59]}$. The confirmed overall response rate assessed by blinded independent central review was $14.3 \%$ (22 of 154 patients), with 3 complete responses (1.9\%) and 19 partial responses (12.3\%). Response duration ranged from 3.2 to more than 38.2 months; $91 \%$ of those patients had responses of 6 months or longer and 55\% had responses lasting 12 months or longer.

Common adverse reactions occurring in more than $20 \%$ of patients included fatigue, rash, musculoskeletal pain, pruritus, diarrhea, nausea, asthenia, cough, dyspnea, constipation, decreased appetite, back pain, arthralgia, upper respiratory tract infection, and pyrexia. Differently for the safety profile previously described in nivolumab label, patients of CheckMate-040 reported a higher incidence of elevations in transaminases and bilirubin levels: treatment-emergent grade 3 or 4 AST was observed in 27 (18\%) subjects, grade 3 or 4 ALT in $16(11 \%)$ patients, and grade 3 or 4 bilirubin in $11(7 \%)$ patients. Immune-mediated hepatitis requiring systemic corticosteroids occurred in $8(5 \%)$ patients ${ }^{[59]}$. 
In September 2017 American Food and Drug Agency granted priority review to nivolumab for HCC and approved it for patients who have previously been treated with sorafenib, at the dosage of $240 \mathrm{mg}$ every 2 weeks. As a condition of accelerated approval, larger phase 3 randomized trials of nivolumab versus sorafenib will be required to verify the clinical benefit of nivolumab for this indication. A randomized, multicenter phase 3 study of nivolumab versus sorafenib as first-line treatment in patients with advanced hepatocellular carcinoma (CheckMate 459) is ongoing with the goal to enroll 726 patients and the estimated primary completion date is October $2018^{[60]}$.

\section{DISCUSSION}

Ten years after sorafenib introduction in HCC scenario, novel knowledge about this mature drug and the availability of four new drugs are opening innovative therapeutic perspectives for patients suffering from this disease.

Firstly, new evidences coming from clinical practice allowed a renovate use of sorafenib in first line setting. In particular, an important recommendation is to remain in therapy for patients experiencing toxicity during the first weeks of therapies. In fact, at the era of the studies SHARP and ASIA PACIFIC, those patients experiencing important adverse events were considered unsuitable to sorafenib and were suggested to permanently discontinue this therapy. Differently, at the present time, prospective and retrospective data seem to indicate that most likely these patients could receive the major benefit to sorafenib. Indeed, prospective studies and retrospective experiences identified toxicities as a probable marker of response to the therapy. This suggest managing patients experiencing toxicities with an appropriate tolerable adverse event protocol, proposing momentary suspensions followed by restart of therapy at lower doses with the aim to generate drug-tolerance. Nevertheless, a small randomised clinical trial, comparing TACE plus external beam radiotherapy (RT) versus sorafenib in patients affected by hepatocellular carcinoma with macroscopic vascular invasion and Child-Pugh A liver function, demonstrated a superiority of the TACE-RT group over sorafenib: at week 12, the PFS rate was $86.7 \%$ vs. $34.3 \%$, with a higher rate of radiologic response ( $33.3 \% v s$. $2.2 \%)$, a better time of progression ( $31 \mathrm{vs.} 11.7$ weeks), and an overall survival of $55 \mathrm{vs} .43$ weeks ${ }^{[61]}$.

The second innovative point of this new era is the solution to the historic unmet need due to lack of second line therapies in HCC patients progressing to sorafenib. In the past 10 years the scanty opportunity for these patients was the re-treatment with higher dose of sorafenib, or the participation in a clinical trial. Presently, regorafenib is the only second line systemic therapy available worldwide in patients progressed on sorafenib. First-line patients with a very severe intolerance to sorafenib unable to follow a tolerable adverse event protocol may will benefit from the lenvatinib, once approved by Health Authorities, because proved to be non-inferior to the standard of care sorafenib and presenting a different toxicity profile. Cabozantinib and nivolumab could be valid second-line options that allow to reach the "embarrassment of riches" also for treating intermediate and advanced stages HCC.

But these new therapeutic options open the dilemma on which second-line should be chosen. A first speculative solution could evaluate survival data observed in pivotal trials of each therapy. Survival benefit data refers that the sequence sorafenib-regorafenib is associated to 26 months, no data have been reported for the sequences sorafenib-cabozantinib and sorafenib-nivolumab. Besides, while regorafenib was evaluated only in patients with sorafenib progression, cabozantinib was studied in population generically progressed to TKIs because CELESTIAL trial enrolled also patients treated with front-line drugs different from the standard of care. Moreover, including in the trial a significant number of patients with two previous regimens, cabozantinib could be evaluated as a third line therapy too. With the goal to achieve the maximum lines of treatment, a possible sequence strategy may include the use of regorafenib in a second line after progression to sorafenib, allowing to reach a third line of therapy with cabozantinib. The role of 
immunotherapy must be still understood, evaluating the efficacy and tolerability data deriving from the ongoing phase 3 studies requested by regulatory agency. These studies have concluded enrollment and final outcomes will be presented in the next months at congresses.

But a more reliable criterion that could guide the choice of such drugs is the evaluation of tolerability profile detected in clinical trials. Consequently, the choice of the second line drug should be tailored based on patients' characteristics, comorbidities and expected toxicity profile associated with each regimen. At this regard, pivotal studies indicated that regorafenib had a sorafenib-like liver toxicity profile with hepatic adverse events resulting like placebo, while cabozantinib increased liver toxicity, as evidenced by the increase in grade $3 / 4$ transaminases of $12 \%$ suggesting attention to patients with very high transaminase values at the baseline. Similarly, nivolumab does not seem to induce the same toxicity seen for the other two drugs (handfoot skin reaction, diarrhea, hypertension), but may have increased liver toxicity, revealed by the increase in grade $3 / 4$ bilirubin.

An additional therapeutic opportunity for the second-line treatment could be represented also by ramucirumab. At the day of writing a press release announced that this drug demonstered efficacy in a phase 3 study conducted on patients pretreated with sorefenib and with AFP $>400 \mathrm{ng} / \mathrm{mL}^{[67]}$.

\section{CONCLUSION}

Improved knowledge of the standard of care and new therapies coming up after 10 years of failure in HCC, trigger new hopes for patients and hepato-oncological community to extend the survival in a disease that remains one of the leading causes of cancer-related deaths around the world. Currently the lack of adequate predictive or potential biomarkers factors makes challenging the identification of patients who will benefit with durable responses from each therapy.

\section{DECLARATIONS}

\section{Authors' contributions}

Conception and manuscript writing, provision of study materials, collection and assembly of data: Giovanis $\mathrm{P}$

Administrative support: D'Ippolito $S$

Data analysis and interpretation: Giovanis P, Pastorelli D

Final approval of manuscript: all authors

\section{Financial support and sponsorship}

This publication has been made possible by the Medical Writing support of dott Roberto Barsanti and dott Maria Cristina Mazzotta (Medical Department - Bayer SpA). No specific funding or grant have been provided for this publication.

\section{Conflicts of interest}

There are no conflicts of interest.

\section{Patient consent}

Not applicable.

\section{Ethics approval}

Not applicable.

\section{Copyright}

(c) The Author(s) 2018. 


\section{REFERENCES}

1. Fischer S, Gillessen S, Rothermundt C. Sequence of treatment in locally advanced and metastatic renal cell carcinoma. Transl Androl Urol 2015;4:310-25.

2. Siegel RL, Miller KD, Jemal A. Cancer statistics, 2017. CA Cancer J Clin 2017;67:7-30.

3. Zhu AX. Systemic therapy of advanced hepatocellular carcinoma: how hopeful should we be? Oncologist 2006;11:790-800.

4. Pinter M, Trauner M, Peck-Radosavljevic M, Sieghart W. Cancer and liver cirrhosis: implications on prognosis and management. ESMO Open 2016;1:e00042.

5. Llovet JM, Ricci S, Mazzaferro V, Hilgard P, Gane E, Blanc JF, de Oliveira AC, Santoro A, Raoul JL, Forner A, Schwartz M, Porta C, Zeuzem S, Bolondi L, Greten TF, Galle PR, Seitz JF, Borbath I, Haussinger D, Giannaris T, Shan M, Moscovici M, Voliotis D, Bruix J, Group SIS. Sorafenib in advanced hepatocellular carcinoma. N Engl J Med 2008;359:378-90.

6. Forner A, Reig M, Bruix J. Hepatocellular carcinoma. Lancet 2018;391:1301-14.

7. Kudo M, Finn RS, Qin S, Han KH, Ikeda K, Piscaglia F, Baron A, Park JW, Han G, Jassem J, Blanc JF, Vogel A, Komov D, Evans TRJ, Lopez C, Dutcus C, Guo M, Saito K, Kraljevic S, Tamai T, Ren M, Cheng AL. Lenvatinib versus sorafenib in first-line treatment of patients with unresectable hepatocellular carcinoma: a randomised phase 3 non-inferiority trial. Lancet 2018;391:1163-73.

8. Bruix J, Qin S, Merle P, Granito A, Huang YH, Bodoky G, Pracht M, Yokosuka O, Rosmorduc O, Breder V, Gerolami R, Masi G, Ross PJ, Song T, Bronowicki JP, Ollivier-Hourmand I, Kudo M, Cheng AL, Llovet JM, Finn RS, LeBerre MA, Baumhauer A, Meinhardt G, Han G, Investigators R. Regorafenib for patients with hepatocellular carcinoma who progressed on sorafenib treatment (RESORCE): a randomised, double-blind, placebo-controlled, phase 3 trial. Lancet 2017;389:56-66.

9. IPSEN Press Release. Ipsen announces that phase 3 CELESTIAL trial of cabozantinib meets primary endpoint of overall survival in patients with advanced hepatocellular carcinoma. Available from: https://www.ipsen.com/websites/IPSENCOM-PROD/wp-content/ uploads/2017/10/16115941/16-10-2017-IPSEN-CELESTIAL-OS-EN-FINAL-FINAL.pdf [Last accessed on 18 Apr 2017].

10. BMS Press Release. Bristol-Myers Squibb's Opdivo ${ }^{\circledR}$ (nivolumab) receives FDA approval for the treatment of hepatocellular carcinoma patients previously treated with sorafenib. Available from: https://news.bms.com/press-release/corporatefinancial-news/bristol-myerssquibbs-opdivo-nivolumab-receives-fda-approval-t [Last accessed on 18 Apr 2017].

11. Faivre S, de Gramont A, Raymond E. Learning from 7 years of experience with sorafenib in advanced HCC: sorafenib better than sorafenib? Target Oncol 2016;11:565-7.

12. Bolondi L, Craxi A, Trevisani F, Daniele B, Di Costanzo GG, Fagiuoli S, Camma C, Bruzzi P, Danesi R, Spandonaro F, Boni C, Santoro A, Colombo M. Refining sorafenib therapy: lessons from clinical practice. Future Oncol 2015;11:449-65.

13. Lin S, Hoffmann K, Schemmer P. Treatment of hepatocellular carcinoma: a systematic review. Liver Cancer 2012;1:144-58.

14. European Association For The Study Of The Liver. EASL-EORTC clinical practice guidelines: management of hepatocellular carcinoma. J Hepatol 2012;56:908-43.

15. Salhab M, Canelo R. An overview of evidence-based management of hepatocellular carcinoma: a meta-analysis. J Cancer Res Ther 2011;7:463-75.

16. Raoul JL, Sangro B, Forner A, Mazzaferro V, Piscaglia F, Bolondi L, Lencioni R. Evolving strategies for the management of intermediatestage hepatocellular carcinoma: available evidence and expert opinion on the use of transarterial chemoembolization. Cancer Treat Rev 2011;37:212-20.

17. Bolondi L, Burroughs A, Dufour JF, Galle PR, Mazzaferro V, Piscaglia F, Raoul JL, Sangro B. Heterogeneity of patients with intermediate (BCLC-B) hepatocellular carcinoma: proposal for a subclassification to facilitate treatment decisions. Semin Liver Dis 2012;32:348-59.

18. Verslype C, Rosmorduc O, Rougier P. Hepatocellular carcinoma: ESMO-ESDO clinical practice guidelines for diagnosis, treatment and follow-up. Ann Oncol 2012;23:vii41-8.

19. Sieghart W, Hucke F, Peck-Radosavljevic M. Transarterial chemoembolization: modalities, indication, and patient selection. $J$ Hepatol 2015;62:1187-95.

20. Raoul JL, Gilabert M, Piana G. How to define transarterial chemoembolization failure or refractoriness: a European perspective. Liver Cancer 2014;3:119-24.

21. Sieghart W, Hucke F, Pinter M, Graziadei I, Vogel W, Muller C, Heinzl H, Trauner M, Peck-Radosavljevic M. The ART of decision making: retreatment with transarterial chemoembolization in patients with hepatocellular carcinoma. Hepatology 2013;57:2261-73.

22. Hucke F, Sieghart W, Pinter M, Graziadei I, Vogel W, Muller C, Heinzl H, Waneck F, Trauner M, Peck-Radosavljevic M. The ARTstrategy: sequential assessment of the ART score predicts outcome of patients with hepatocellular carcinoma re-treated with TACE. $J$ Hepatol 2014;60:118-26.

23. Llovet JM, Finn RS. Negative phase 3 study of (90)Y microspheres versus sorafenib in HCC. Lancet Oncol 2018;19:e69.

24. Vilgrain V, Pereira H, Assenat E, Guiu B, Ilonca AD, Pageaux GP, Sibert A, Bouattour M, Lebtahi R, Allaham W, Barraud H, Laurent V, Mathias E, Bronowicki JP, Tasu JP, Perdrisot R, Silvain C, Gerolami R, Mundler O, Seitz JF, Vidal V, Aube C, Oberti F, Couturier O, Brenot-Rossi I, Raoul JL, Sarran A, Costentin C, Itti E, Luciani A, Adam R, Lewin M, Samuel D, Ronot M, Dinut A, Castera L, Chatellier G, Group ST. Efficacy and safety of selective internal radiotherapy with yttrium-90 resin microspheres compared with sorafenib in locally advanced and inoperable hepatocellular carcinoma (SARAH): an open-label randomised controlled phase 3 trial. Lancet Oncol 2017;18:1624-36.

25. Chow PK, Gandhi M, Gebski V. The SIRveNIB and SARAH trials and the role of SIR-Spheres(R) Y-90 resin microspheres in the management of hepatocellular carcinoma. Future Oncol 2017;13:2213-6.

26. Cheng AL, Kang YK, Chen Z, Tsao CJ, Qin S, Kim JS, Luo R, Feng J, Ye S, Yang TS, Xu J, Sun Y, Liang H, Liu J, Wang J, Tak WY, Pan H, Burock K, Zou J, Voliotis D, Guan Z. Efficacy and safety of sorafenib in patients in the Asia-Pacific region with advanced hepatocellular carcinoma: a phase III randomised, double-blind, placebo-controlled trial. Lancet Oncol 2009;10:25-34.

27. Forner A, Llovet JM, Bruix J. Hepatocellular carcinoma. Lancet 2012;379:1245-55. 
28. Bruix J, Cheng AL, Meinhardt G, Nakajima K, De Sanctis Y, Llovet J. Prognostic factors and predictors of sorafenib benefit in patients with hepatocellular carcinoma: analysis of two phase III studies. J Hepatol 2017;67:999-1008.

29. Kudo M, Lencioni R, Marrero JA, Venook AP, Bronowicki JP, Chen XP, Dagher L, Furuse J, Geschwind JF, Ladron de Guevara L, Papandreou C, Sanyal AJ, Takayama T, Yoon SK, Nakajima K, Lehr R, Heldner S, Ye SL. Regional differences in sorafenib-treated patients with hepatocellular carcinoma: GIDEON observational study. Liver Int 2016;36:1196-205.

30. Iavarone M, Cabibbo G, Piscaglia F, Zavaglia C, Grieco A, Villa E, Camma C, Colombo M; SOFIA (SOraFenib Italian Assessment) study group. Field-practice study of sorafenib therapy for hepatocellular carcinoma: a prospective multicenter study in Italy. Hepatology 2011;54:2055-63.

31. Ponziani FR, Bhoori S, Germini A, Bongini M, Flores M, Sposito C, Facciorusso A, Gasbarrini A, Mazzaferro V. Inducing tolerability of adverse events increases sorafenib exposure and optimizes patient's outcome in advanced hepatocellular carcinoma. Liver Int 2016;36:1033-42.

32. Reig M, Torres F, Rodriguez-Lope C, Forner A, NLL, Rimola J, Darnell A, Rios J, Ayuso C, Bruix J. Early dermatologic adverse events predict better outcome in HCC patients treated with sorafenib. J Hepatol 2014;61:318-24.

33. Bettinger D, Schultheiss M, Knuppel E, Thimme R, Blum HE, Spangenberg HC. Diarrhea predicts a positive response to sorafenib in patients with advanced hepatocellular carcinoma. Hepatology 2012;56:789-90.

34. Otsuka T, Eguchi Y, Kawazoe S, Yanagita K, Ario K, Kitahara K, Kawasoe H, Kato H, Mizuta T; Saga Liver Cancer Study Group. Skin toxicities and survival in advanced hepatocellular carcinoma patients treated with sorafenib. Hepatol Res 2012;42:879-86.

35. Estfan B, Byrne M, Kim R. Sorafenib in advanced hepatocellular carcinoma: hypertension as a potential surrogate marker for efficacy. Am J Clin Oncol 2013;36:319-24.

36. Vincenzi B, Santini D, Russo A, Addeo R, Giuliani F, Montella L, Rizzo S, Venditti O, Frezza AM, Caraglia M, Colucci G, Del Prete $\mathrm{S}$, Tonini G. Early skin toxicity as a predictive factor for tumor control in hepatocellular carcinoma patients treated with sorafenib. Oncologist 2010;15:85-92.

37. Kudo M. Locoregional therapy for hepatocellular carcinoma. Liver Cancer 2015;4:163-4.

38. Lencioni R, Llovet JM, Han G, Tak WY, Yang J, Guglielmi A, Paik SW, Reig M, Kim DY, Chau GY, Luca A, Del Arbol LR, Leberre MA, Niu W, Nicholson K, Meinhardt G, Bruix J. Sorafenib or placebo plus TACE with doxorubicin-eluting beads for intermediate stage HCC: the SPACE trial. J Hepatol 2016;64:1090-8.

39. Bruix J, Takayama T, Mazzaferro V, Chau GY, Yang J, Kudo M, Cai J, Poon RT, Han KH, Tak WY, Lee HC, Song T, Roayaie S, Bolondi L, Lee KS, Makuuchi M, Souza F, Berre MA, Meinhardt G, Llovet JM; STORM investigators. Adjuvant sorafenib for hepatocellular carcinoma after resection or ablation (STORM): a phase 3, randomised, double-blind, placebo-controlled trial. Lancet Oncol 2015;16:1344-54.

40. Zhong JH, Du XK, Xiang BD, Li LQ. Adjuvant sorafenib in hepatocellular carcinoma: a cautionary comment of STORM trial. World $J$ Hepatol 2016;8:957-60.

41. Geschwind JH, Chapiro J. Sorafenib in combination with transarterial chemoembolization for the treatment of hepatocellular carcinoma. Gastroenterol Hepatol 2016;12:504-6.

42. NCT02529761. TACE With or Without Sorafenib in Intermediate Stage Hepatocellular Carcinoma. Available from: https://clinicaltrials. gov/ct2/show/NCT02529761 [Last accessed on 18 Apr 2018].

43. NCT03097848. Efficacy and Safety of Sorafenib as Adjuvant and Latter Radiofrequency Ablation for Recurrent Hepatocellular Carcinoma (ESCALATOR). Available from: https://clinicaltrials.gov/ct2/show/NCT03097848 [Last accessed on 18 Apr 2018].

44. NCT02436902. Adjuvant Therapies for Patients With HCC and MVI (A-TACE/S-HCC). Available from: https://clinicaltrials.gov/ct2/ show/NCT02436902 [Last accessed on 18 Apr 2018].

45. Zhu AX, Rosmorduc O, Evans TR, Ross PJ, Santoro A, Carrilho FJ, Bruix J, Qin S, Thuluvath PJ, Llovet JM, Leberre MA, Jensen M, Meinhardt G, Kang YK. Search: a phase III, randomized, double-blind, placebo-controlled trial of sorafenib plus erlotinib in patients with advanced hepatocellular carcinoma. J Clin Oncol 2015;33:559-66.

46. Abou-Alfa GK, Johnson P, Knox JJ, Capanu M, Davidenko I, Lacava J, Leung T, Gansukh B, Saltz LB. Doxorubicin plus sorafenib vs doxorubicin alone in patients with advanced hepatocellular carcinoma: a randomized trial. JAMA 2010;304:2154-60.

47. Treating Advanced Hepatocellular Carcinoma in 2018. Available from: https://gicasym.org/daily-news/treating-advanced-hepatocellularcarcinoma-2018 [Last accessed on 18 Apr 2018].

48. Abou-Elkacem L, Arns S, Brix G, Gremse F, Zopf D, Kiessling F, Lederle W. Regorafenib inhibits growth, angiogenesis, and metastasis in a highly aggressive, orthotopic colon cancer model. Mol Cancer Ther 2013;12:1322-31.

49. Bruix J, Tak WY, Gasbarrini A, Santoro A, Colombo M, Lim HY, Mazzaferro V, Wiest R, Reig M, Wagner A, Bolondi L. Regorafenib as second-line therapy for intermediate or advanced hepatocellular carcinoma: multicentre, open-label, phase II safety study. Eur J Cancer 2013;49:3412-9.

50. Bruix J, Qin S, Merle P, Granito A, Huang YH, Bodoky G, Pracht M, Yokosuka O, Rosmorduc O, Breder V, Gerolami R, Masi G, Ross PJ, Song T, Bronowicki JP, Ollivier-Hourmand I, Kudo M, Cheng AL, Llovet JM, Finn RS, LeBerre MA, Baumhauer A, Meinhardt G, Han G. Regorafenib for patients with hepatocellular carcinoma who progressed on sorafenib treatment (RESORCE): a randomised, double-blind, placebo-controlled, phase 3 trial. Lancet 2016;6736:32453-9

51. Finn RS, Merle P, Granito A, Huang YH, Bodoky G, Pracht M, Yokosuka O, Rosmorduc O, Gerolami R, Caparello C, Cabrera R, Chang C, Sun W, Han G, Le Berre MA, Baumhauer A, Meinhardt G, Bruix J; the RESORCE Investigators. Outcomes with sorafenib (SOR) followed by regorafenib (REG) or placebo (PBO) for hepatocellular carcinoma (HCC): results of the international, randomized phase 3 RESORCE trial. J Clin Oncol 2017;35 suppl 4:abstr344.

52. Lorusso L, Pieruzzi L, Biagini A, Sabini E, Valerio L, Giani C, Passannanti P, Pontillo-Contillo B, Battaglia V, Mazzeo S, Molinaro E, Elisei R. Lenvatinib and other tyrosine kinase inhibitors for the treatment of radioiodine refractory, advanced, and progressive thyroid cancer. Onco Targets Ther 2016;9:6467-77. 
53. Motzer RJ, Hutson TE, Ren M, Dutcus C, Larkin J. Independent assessment of lenvatinib plus everolimus in patients with metastatic renal cell carcinoma. Lancet Oncol 2016;17:e4-5.

54. Ikeda K, Kudo M, Kawazoe S, Osaki Y, Ikeda M, Okusaka T, Tamai T, Suzuki T, Hisai T, Hayato S, Okita K, Kumada H. Phase 2 study of lenvatinib in patients with advanced hepatocellular carcinoma. J Gastroenterol 2017;52:512-9.

55. Kudo M, Finn RS, Qin S, Han KH, Ikeda K, Piscaglia F, Baron A, Park JW, Han G, Jassem J, Blanc JF, Vogel A, Komov D, Evans TRJ, Lopez C, Ditcus C, Guo M, Saito K, Kraljevic S, Tamai T, Ren M, Cheng AL. Lenvatinib versus sorafenib in first-line treatment of patients with unresectable hepatocellular carcinoma: a randomised phase III non-inferiority trial. Lancet 2018;391:1163-73.

56. Markowitz JN, Fancher KM. Cabozantinib: a multitargeted oral tyrosine kinase inhibitor. Pharmacotherapy 2018;38:357-69.

57. Kelley RK, Verslype C, Cohn AL, Yang TS, Su WC, Burris H, Braiteh F, Vogelzang N, Spira A, Foster P, Lee Y, Van Cutsem E. Cabozantinib in hepatocellular carcinoma: results of a phase 2 placebo-controlled randomized discontinuation study. Ann Oncol 2017;28:528-34.

58. Abou-Alfa GKMT, Cheng AL. Cabozantinib (C) versus placebo (P) in patients (pts) with advanced hepatocellular carcinoma (HCC) who have received prior sorafenib: results from the randomized phase III CELESTIAL trial. J Clin Oncol 2018;36:207.

59. El-Khoueiry AB, Sangro B, Yau T, Crocenzi TS, Kudo M, Hsu C, Kim TY, Choo SP, Trojan J, Welling THR, Meyer T, Kang YK, Yeo W, Chopra A, Anderson J, Dela Cruz C, Lang L, Neely J, Tang H, Dastani HB, Melero I. Nivolumab in patients with advanced hepatocellular carcinoma (CheckMate 040): an open-label, non-comparative, phase 1/2 dose escalation and expansion trial. Lancet 2017;389:2492-502.

60. NCT02576509. An Investigational Immuno-therapy Study of Nivolumab Compared to Sorafenib as a First Treatment in Patients With Advanced Hepatocellular Carcinoma. Available from: https://clinicaltrials.gov/ct2/show/NCT02576509 [Last accessed on 18 Apr 2018].

61. Yoon SM, Ryoo BY, Lee SJ, Kim JH, Shin JH, An JH, Lee HC, Lim YS. Efficacy and safety of transarterial chemoembolization plus external beam radiotherapy vs sorafenib in hepatocellular carcinoma with macroscopic vascular invasion: a randomised clinical trial. JAMA Oncol 2018; doi: 10.1001/jamaoncol.2017.5847.

62. Kudo M, Izumi N, Kokudo N, Matsui O, Sakamoto M, Nakashima O, Kojiro M, Makuuchi M. Management of hepatocellular carcinoma in Japan: consensus-based clinical practice guidelines proposed by the Japan Society of Hepatology (JSH) 2010 updated version. Dig Dis 2011;29:339-63.

63. Yamanaka K, Hatano E, Kitamura K, Iida T, Ishii T, Machimoto T, Taura K, Yasuchika K, Isoda H, Shibata T, Uemoto S. Early evaluation of transcatheter arterial chemoembolization-refractory hepatocellular carcinoma. J Gastroenterol 2012;47:343-6.

64. Italian Association for the Study of the Liver (AISF), AISF Expert Panel, AISF Coordinating Committee. Position paper of the Italian Association for the Study of the Liver (AISF): the multidisciplinary clinical approach to hepatocellular carcinoma. Dig Liver Dis 2013;45:712-23.

65. Verslype C, Rosmorduc O, Rougier P. Hepatocellular carcinoma: ESMO-ESDO clinical practice guidelines. Ann Oncol 2012;23:vii41-8.

66. Bruix J, Morris Sherman M. AASLD PRACTICE GUIDELINE management of hepatocellular carcinoma: an update. Hepatology 2011;53:1020-2.

67. PR Newswire Release. Lilly Announces CYRAMZA®) (ramucirumab) Phase 3 REACH-2 Study in Second-Line Hepatocellular Carcinoma Patients Met Overall Survival Endpoint. Available from: https:/www.prnewswire.com/news-releases/lillyannounces-cyramza-ramucirumab-phase-3-reach-2-study-in-second-line-hepatocellular-carcinoma-patients-met-overall-survivalendpoint-300624113.html [Last accessed on 19 Apr 2018]. 